\title{
A Reflexive Model of ICT Practices in Organizations
}

\author{
Jan-Oddvar Sørnes \\ Bodø Graduate School of Business \\ Bodø, Norway \\ Jan.Oddvar.Soernes@hibo.no
}

\author{
Larry Davis Browning \\ The University of Texas at Austin \\ Austin, TX, USA
}

lbrowning@mail.utexas.edu

\author{
Keri Keilberg Stephens \\ Texas State University \\ San Marcos, TX, USA \\ ks33@txstate.edu
}

\author{
Alf Steinar Sætre \\ Norwegian University of Science \\ and Technology, Trondheim, \\ Norway \\ alfs@iot.ntnu.no
}

\begin{abstract}
This paper reports a study of information and communication technology (ICT) use in Norway and the United States. Forty-two depth interviews completed in both countries provide the data source. Using grounded theory as a research method, and Adaptive Structuration Theory as our conceptual base, we analyze these interviews to generate an empirical model of ICT use. The 1490 incidents identified in our analysis are first reduced to 49 categories. These categories are further reduced to four: satisficing, communication channels, communication structure, and environmental agents. These four categories comprise the major parts of the reflexive model. The findings suggest that the parts of the model are interdependent and mutually causal in that individuals consider and even reconsider the use of multiple communication channels within and between tasks. As a conclusion we address future research including, credibility and time issues in ICT use.
\end{abstract}

Keywords: media choice, organizational communication, cross-cultural communication, adaptive structuration theory, reflexivity.

\section{Introduction}

Traditionally, empirical studies that have looked at information and communication technologies (ICTs) in organizations such as email, fax, voicemail, and the telephone have adopted both a deterministic focus and a quantitative methodology. As illuminating as these studies have proved

Material published as part of this journal, either online or in print, is copyrighted by the publisher of Informing Science. Permission to make digital or paper copy of part or all of these works for personal or classroom use is granted without fee provided that the copies are not made or distributed for profit or commercial advantage AND that copies 1) bear this notice in full and 2) give the full citation on the first page. It is permissible to abstract these works so long as credit is given. To copy in all other cases or to republish or to post on a server or to redistribute to lists requires specific permission and payment of a fee. Contact Editor@inform.nu to request redistribution permission. with respect to identifying when particular communication channels are most apt to be chosen, they have tended to produce inconsistent findings. Why? Because, as later studies showed, more than just technology itself shapes ICT use (Contractor \& Eisenberg, 1990; Fulk, Schmitz, \& Steinfield, 1990; Markus, 1990; Poole \& DeSanctis, 1990; Sitkin, Sutcliffe, $\&$ Barrios-Choplin, 1992). So in the 
past decade scholars have moved away from controlled studies and consequently produced a wealth of qualitative research and recursive theorizing. In the process, many different theories have emerged to explain how the various elements work together to explain ICT use (Hollingshead \& Contractor, 2002; Kling, 1996; Markus \& Robey, 1988; Spear \& Lea, 1994; Webster \& Trevino, 2000). However, it is rare to find studies looking at multiple ICTs in combination, and those that exist have thus far used predominantly college students as their survey respondents (e.g., Flanagin \& Metzger, 2001; Savolainen, 1999). We intend to capitalize on the need to study many ICTs in context. Sitkin et al. (1992) claim that much of the ICT literature facilely assumes that users employ a single ICT for a given task. They argue - rightly, we believe - that studies of multiple channels and communicators offer a solid place for future researchers to tread.

Our approach follows this recent trend and uses an inductive process to empirically extend these recent theoretical models. We extend existing empirical research by collecting diverse data that involves the use of multiple ICTs in 10 industries, 30 organizations, multiple levels of management, and different job roles.

The qualitative approach we use - a grounded theory methodology (Charmaz, 2000; Glaser \& Strauss, 1967) - compels us to actually go into the field and gather our data first before hypothesizing about the relationships. We interview the agents, we allow them to put forth the ICTs they themselves use, we listen to them explain their interactions with what or whom, and then we move from details to abstractions in the production of theory. There is some previous work using grounded theory to examine ICTs (Orlikowski, 1993; Scott, 1998). Scott (1998), for instance, analyzed ICT use by assessing secondary sources. She searched the Internet for case studies of Internet use, examined websites provided by vendors such as Netscape and Sun, and she reviewed articles by consultants and academics. Her work with secondary sources foreshadows this research, since we extend her analysis and rely on primary sources by conducting interviews with active ICT users.

While grounded theory provides us our methodological framework to generate our theory, we rely on existing theory to help us make sense of our data and add reliability to our findings. We use Giddens' structuration theory $(1979,1984,1987,1990)$, and in particular one of his primary tenets, the duality of structure, to explain the relationship between action and structure in a complex information environment. In particular, we build on Adaptive Structuration Theory (AST) (Poole \& DeSanctis, 1990) to show how individuals appropriate ICTs for their own use, which is at the heart of the grounded model presented later in this paper.

Because the literature on ICT use and its sister terms is substantial (for reviews, see Fulk \& Boyd, 1991; Flanagin \& Metzger, 2001; Garton \& Wellman, 1995; Hollingshead \& Contractor, 2002), we will restrict our review of it to those studies that have shaped our guiding research question and that situate our reflexive model. We will then explain in greater detail the methods we've employed. Next, we present the theoretical perspectives of structuration theory to form a framework for interpreting the findings. Then, the findings are presented and are organized around the four central nodes in our model (see Figure 1). Finally, we end with a summary and conclusions.

\section{Literature Review}

To best situate current research on ICT use, we begin with a brief review of the theoretical and empirical literature. Much of the previous work treats technology as a firmly imbedded structure that itself determines how a particular channel will be used (i.e., media richness theory (Daft \& Lengel, 1984; Daft, Lengel \& Trevino, 1987; Trevino, Daft \& Lengel, 1990), social presence theory (Short, Williams \& Christie, 1976), and the cues-filtered-out perspective theory (Sproull \& Kiesler, 1986)). 
More recently, theorists have challenged the notion of technological determinism by suggesting that channels are best studied through a lens of social influence (Fulk, Schmitz, \& Steinfield, 1990), a process capable of carrying task data and symbolic meaning (Sitkin et al., 1992), and a socially constructed, or co-determinant perspective (Contractor \& Eisenberg, 1990; Fulk, Schmitz \& Steinfield, 1990; Markus, 1990; Markus \& Robey, 1988; Poole \& DeSanctis, 1990; Zack \& Mckenney, 1995). Social construction attempts to move beyond the deterministic views to recognize that features of technology are enacted and emergent, not embodied, in a given channel. Specifically, adaptive structuration theory (AST) examines how the structures that are imposed by technology recursively shape and in turn are shaped by interaction (Pool \& DeSanctis, 1990). Orlikowski (2000) attempts to move beyond the perspectives of AST and calls these features of technology "technologies in practice" (p. 407) and uses AST (Poole \& DeSanctis, 1990) to argue that ongoing enactment of a technology in practice explains why users may need to use technology differently if they change jobs or have new communication responsibilities. This social construction perspective serves as the basis for our guiding research question here, one that will provide additional empirical tests of this perspective and expand the examination to include multiple organizations.

Thus, we propose the following research question:

In organizational contexts, what factors influence individuals' media use when they select among the various ICTs?

\section{Method}

Given the paucity of empirical research on the use of multiple ICTs in organizations, we chose a qualitative approach to answer the research question listed above. This is consistent with suggestions by Steinfield and Fulk (1990) that these phenomena should be explored in the field using a qualitative methodology. A qualitative method of inquiry is preferable wherever the topic of inquiry is emergent and ill-defined (Patton, 1990). Strauss and Corbin (1990) explain that qualitative research is useful for giving "intricate details of phenomena that are difficult to convey with quantitative methods" (p. 19). Also, grounded theory is particularly adept at registering variation because of the flexibility it gives researchers to modify their analyses as further data are gathered (Charmaz, 2000). Thus, by conducting field research, we are better able to capture how individuals use various ICTs.

\section{Research Sites and Participants}

The participants in our study were chosen by a theoretical sampling procedure whereby individual respondents were chosen based on their experiences, ability to reflect, and ability to articulate the information solicited (Glaser \& Strauss, 1967). Apart from their uniformity in age (all but three of them were younger than 40), participants consisted of a cross-section of users (maximum deviation) representing different functional areas (i.e. managers, salespeople, marketers, programmers, web-designers), ethnicities, professional and organizational tenure, and gender. We had two particularly relevant criteria for selecting participants: (a) all of them used ICTs extensively in their daily work, and (b) they frequently communicated with either internal or external customers. This last feature becomes important in our data set because few studies make an effort to collect data from sales and marketing (externally focused communication) as well as production (internally focused communication). The sample consisted of people working for organizations based in the U.S. and Norway who represented diverse industries, including e-learning, entertainment, software-production, semiconductor, oil and gas, and government agencies. 


\section{Data Collection Procedures}

Data was collected using semi-structured, in-depth interviews - a method that is flexible and that favors adaptation to each context and individual. Moreover, it's important to note that we did not enter the field as blank slates with respect to our understanding of the phenomena of interest (Strauss \& Corbin, 1990). We researched the literature to provide a manageable direction to the study.

An interview guide was created based on Spradley's (1979) "grand tour interview design" to initiate the interview, and perhaps most importantly, allowed the participants to structure the phenomenon of interest rather than the interviewer. Interviewees were encouraged to tell the "story" of their technology use to ensure the inclusion of outlying details (Polster, 1987). To further ensure this richness, participants were first informed about the study, and then asked to think of one or more specific projects that they were currently working on or had completed. The interview guide began with a set of pre-defined questions focusing on how participants use ICTs in their daily work as well as more general inquiries about collaborative processes with both internal and external customers.

Over the course of five months, four researchers conducted a total of 42 individual interviews, including 21 in the US and 21 in Norway. Each interview lasted 45-90 minutes and was audiorecorded. The recordings were then transcribed, resulting in some 1,100 pages of double spaced text. To facilitate subsequent data analysis, the Norwegian data set was translated into English by the primary Norwegian interviewer. The other Norwegian research team member checked these translations for semantic and contextual accuracy. Simultaneously with the observations and interviews, we followed the standard recommendation to review the existing literature and thus validate our theoretical perspectives (Charmaz, 2000; Glaser \& Strauss, 1967).

\section{Qualitative data analysis}

We started by identifying individual units of data — called "incidents"—ranging from single sentences to short paragraphs. We used topic change as the demarcation for establishing incidents. This initial process of labeling incidents is helpful for synthesizing the many observations and for providing insight into our research questions. The second step involved focused coding (Glaser, 1978), where we sorted incidents into a category system in order to generate a smaller, more manageable representation of the data - resulting in 48 categories to further analyze (see Table 1).

Table 1: Total Category Listing.

\begin{tabular}{|l|l|}
\hline 1. What the Web Adds to the Sales Process & 25. Video Conferencing \\
\hline 2. E-mail Norms & 26. How a Web Site Establishes Culture \\
\hline 3. Reliability of Sources & 27. Just-In-Time Learning \\
\hline 4. Face-to-Face (FtF) Communication & 28. Physical Work Environment \\
\hline $\begin{array}{l}\text { 5. How the Web Affects Organizational Process } \\
\text { (Other Than Sales) }\end{array}$ & 29. Internet Search Skills \\
\hline 6. The Value of Traditional Sales Practices & 30. Rules of Internet Use \\
\hline 7. Collaborative Innovation & 31. Receiver Communication Preference \\
\hline 8. Competitive Intelligence & 32. Work/Fun/Flow \\
\hline 9. Desire for Future Technology & 33. Complexity \& Uncertainty \\
\hline 10. Selecting the Right ICT Channel for the Task & 34. Technical Issues \\
\hline 11. Sequence of Media Choice & 35. Technology Adoption \\
\hline 12. Telephone Norms & 36. Communication in General \\
\hline
\end{tabular}




\begin{tabular}{|l|l|}
\hline 13.Internal Digital Knowledgebase & 37. Anonymity \\
\hline 14. Role of PowerPoint ${ }^{\circledR}$ & 38. Cooperative Analysis \\
\hline 15. Preponderance of the Web & 39. E-commerce \\
\hline 16. Customer Relationship Management CRM) & 40. Portability of ICTs \\
\hline 17. E-Learning \& General Training & 41. Combinatorial and Iterative Process \\
\hline 18. Information Organization & 42. Learning by Failure \\
\hline 19. Time Considerations & 43. The Web's Role in Decision-Making \\
\hline 20. Information Overload & 44. Hierarchy \\
\hline 21. Generation Gap of Users & 45. Value of the Internet \\
\hline 22. Control & 46. Information Obsolescence \\
\hline 23. Use of Paper & 47. Limited Search \\
\hline 24. Palm Pilot & 48. The Demise of Fax \\
\hline
\end{tabular}

Glaser and Strauss (1967) refer to this reduction process as one of the vital procedures in discovering what they term core categories. Since this is a more conceptual treatment of the data, we examined each category to determine if it signified an event, a relationship, or a process, and also if it possibly connected with other categories. This reduced our total number of coded categories from 48 to four core categories, which we will call "nodes." These four nodes are a comprehensive representation of the 48 categories.

After the reduction process, where our four core categories emerged, we sampled and integrated the literature to further develop the emerging theory (Browning \& Folger, 1994; Glaser \& Strauss, 1967). Integration involves searching for underlying uniformities in the nodes that represent the theory derived from the qualitative data (Browning \& Folger, 1994). This step elaborates upon the category system by writing abstractly about it. In this phase, the nodes were renamed and tied to existing theoretical literature to widen the findings' application (Browning \& Folger, 1994). Comparing our core categories to the existing literature, such as structuration theory and adaptive structuration theory, helped us define them more accurately and link them to one another. It is important to emphasize that these theoretical frameworks were not used to guide our data collection or initial analysis of our data. The final four nodes were then mapped into a theoretical model (see Figure 1) to depict more graphically their relationships.

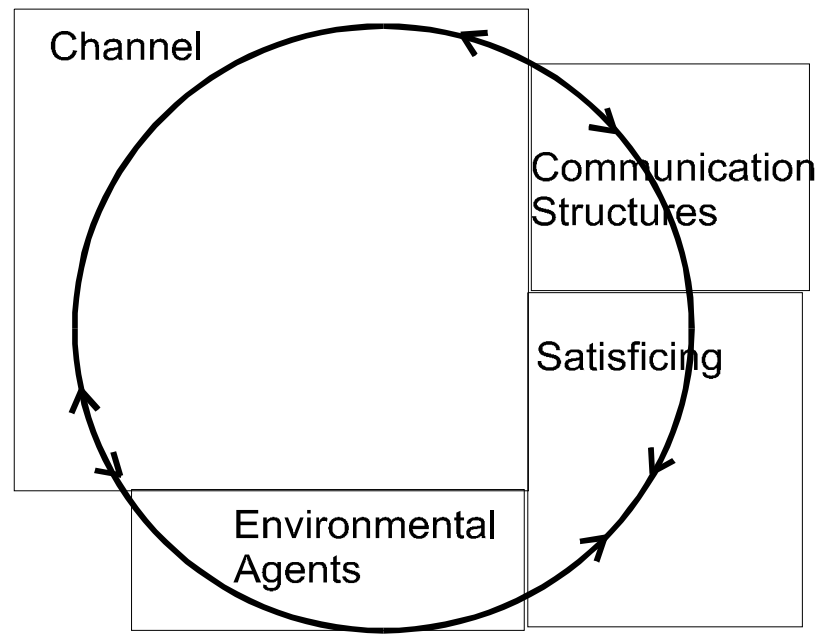

Figure 1: The Reflexive Model of ICT Use 


\section{Using AST as a Theoretical Framework}

To develop the theoretical scaffolding for the findings generated from the grounded theory analysis, we link it to Adaptive Structuration Theory (AST). We will assert that AST help explain our data, for it captures how systems evolve as action and structure emerge reflexively-in other words, as an action creates structure that in turn becomes the basis for further action (Taylor, 2001). After reviewing this theoretical perspective, we introduce the model and elaborate on the four major parts. Finally, we conclude with some directions for future research.

\section{Adaptive Structuration Theory}

Structuration theory extends a set of ideas organized around the writing of Anthony Giddens $(1979,1984,1987,1990)$, who focuses on how designed arrangements, like technology and processes, both constrain and sanction individual action in organizations (Poole, Seibold, \& McPhee, 1985). Structuration theory is attractive to researchers because it helps answer the question of how different types of communication compose the structures in which actors participate (Ranson, Hinings, \& Greenwood, 1980; Taylor, 2001).

Thus far, structuration theory has been applied to the study of organizational communication for myriad purposes. For example, it has been used to account for the effects of power on organizational arrangements (Riley, 1983); to analyze the interpretive schemes that lead individuals to construct meaning (Poole et al., 1985); to show how the same technology can produce similar structuring and divergent outcomes and hierarchies (Barley, 1986); to assess how organizational climates change over time (Bastien, McPhee, \& Bolton, 1995); to examine dialectical processes in organizational change (Howard \& Geist, 1995); and to understand structuring processes in a research consortium (Browning \& Beyer, 1998; Browning, Beyer, \& Shetler, 1995; Browning \& Shetler, 2000).

In addition, scholars have built on structuration theory and expanded its usefulness to communication and group-level analysis through the development of AST. It is this extension of structuration theory by Poole and DeSanctis and others' work (Chin, Gopal, \& Salisbury, 1997; Contractor \& Seibold, 1993; DeSanctis \& Poole, 1994; DeSanctis, Poole, Dickson, \& Jackson, 1993; DeSanctis, Snyder, \& Poole, 1994; Poole \& DeSanctis, 1989, 1990, 1992; Poole, DeSanctis, Kirsch, \& Jackson, 1994; Scott, Quinn, Timmerman, \& Garrett, 1998) that applies most directly to this research. Previously, most AST research has focused on the performance of group-decision support systems (GDSS) and related technologies. Our research extends the reach of AST by offering a perspective on how individuals appropriate technology when they have many ICT options. AST lets researchers study how ICTs change organizations by focusing not only on the various structures that technology provides, but also on those structures that emerge when people interact with technology (DeSanctis \& Poole, 1994). Following are five tenets of AST as they specifically apply to the major findings in the current study.

First, structuration is the process by which groups maintain a system through applying structures that are the rules and resources provided by sources such as the organization, the task, the organizational culture, the group norms, and the knowledge represented by the participants (Chin et al., 1997). Our interviewees used rules and resources such as the technology provided by the organization and culture to create guiding structures. They also accepted the norms, and acknowledged that their own understanding of the technology affected their practices. While these interviewees are not technology boosters, they represent themselves as competent and active technology users.

Second, the potential of any technology is open-ended. Although it isn't difficult to list a tool's intended functions, its actual uses prove as varied as the goals it supports (DeSanctis et al., 1993). While our interviewees talk frequently about how they use technology to achieve their goals, no 
two interviews offer a particular pattern of likeness. Instead, the interviewees vary sharply in the strategies they report using - especially the sequence in which they use them.

Third, users have agency in that they constitute, give meaning, and add value to technologies (Taylor, 1986). Until applied by a user in a specific context, technology is "simply dead matter" (Poole \& DeSanctis, 1990, p. 178). Probably because our sampling of interviewees called for active users, we don't have "dead matter" in these reports of practice. All our interviewees reported high use. This report from one interviewee demonstrates this: "If the computer is down and you can't use the email, you might as well go home."

Fourth, the recursive interplay among actors, goals, and technologies in an emergent system must account for how specific user groups assimilate technologies within their own streams of work activity (Contractor \& Seibold, 1993). Our model represents the recursive interplay throughout the data, and even though these people varied in their use of ICT technology, they all had rationales for the actions they took.

Fifth, appropriation is the process of bringing structures into practice via interaction. It has three aspects: (a) the amount of appropriation, or the extent to which the group uses the methodology to complete tasks; (b) the distribution of appropriation, which is the degree to which members are equally likely to use the method in problem-solving; and (c) appropriation moves, which concerns whether members use procedures in the prescribed way or whether they combine them with other methods or otherwise change them to fit the task (DeSanctis et al., 1993). All the components of appropriation are present here; therefore, we will elaborate on each of the three aspects.

As noted earlier in this paper, the amount of appropriation is high here in that these interviewees use ICTs with little or no resistance and talk about their use with pride and ownership. Also, they use ICTs at both work and play_-indeed, almost interchangeably. Like Boulding's "squirrel's law" (Boulding, 1989, p. 673), it's often difficult to distinguish between work and play. Using ICTs for both purposes clearly tends to minimize any stress associated with their use. Only one person mentioned worrying about the stress resulting from spending too much time on ICTs.

The distribution of appropriation, meanwhile, is wide in that interviewees report very different approaches to media choice. Appropriation moves are also included in our analysis in that while people use most of their ICTs in routine ways, they also talk of distinctions. Individuals use ICTs in ways that are uniquely individualistic in addition to adapting the technology to their own purposes and changing situations.

\section{The Theoretical Explanation of the Model}

The model presented below depicts the relations among major nodes, including categories within and across nodes, and are considered to be interdependent and mutually causal. Any single category, including a minor one composed of only three examples, has the potential to influence and act causally on other categories and nodes - just as three drops of Tabasco sauce can change a bowl of soup.

As explained earlier, the four core categories uncovered in our grounded theory analysis represent a grand synthesis of the 48 original categories. They make up the different nodes on the reflexive ICT use model. The bi-directional arrows within the model represent the potentially dynamic relationships among the four major nodes. Unlike proponents of media richness and social influence theories, which often assume the use of a single channel for any given task, we argue that individuals may, in fact, consider and even reconsider using multiple channels.

In response to our research question regarding the factors that affect channel choice, four nodes emerged from the data: (1) channel options, (2) communication structures, (3) satisficing, and (4) 
environmental agents (see Table 2). These are the four nodes that reflexively interact. We now discuss each of the nodes and provide narrative examples of the more relevant categories.

Table 2: Nodes within the Model and Prevalent Category Descriptions and total incidents

\section{Channels}

-What the Web Adds to Sales Process (177)

Discusses how the Web has changed the sales process. For example, prospecting has been sped up, as has the information flow between people involved in the sale.

-Face to Face Communication (104)

Discusses FtF's role in the computer-mediated environment. Also discusses FtF's appropriateness, quality, and frequency of use.

-Selecting the right channel (52)

Discusses how different media and channels are chosen to carry out a task (e.g., contacts), including the most efficient way of communicating with internal and external customers.

-E-mail Norms (129)

Describes how interviewees use e-mail as their chief medium of communication. Discusses issues such as appropriateness, e-mail use for information-sharing, and CYA (self-protective) tendencies.

\section{Communication Structures}

-Collaborative Innovation (81)

Includes formal and informal information-seeking and information-sharing behaviors from channels such as discussion boards, people (colleagues, customers, suppliers, competitors), corporate Intranets, and the Internet.

-Information Organization (24)

Discusses the importance of being able to store, organize, and easily access lots of information. Includes a desire expressed for a software product to provide that organization.

-Generation Gap of Users (16)

Discusses how older people are generally more skeptical and old-fashioned in dealing with technology.

\section{Satisficing}

-Reliability of Sources (121)

Credibility \& Trust - Includes the need for credible information sources, how source credibility is assessed, and the expressed common characteristics of credible sources. Also includes information on trust building and the importance of trust.

-Value of traditional sales practices (92)

Shows how many elements of the traditional sales process remain both valid and useful, even with ICTs. Examples include gaining access to decision-makers, 
Sørnes, Stephens, Browning \& Sætre

relying on customer referrals, and determining demo

appropriateness.

-Role of PowerPoint (29)

Besides being a presentation tool, PowerPoint is widely

used for consolidating and organizing information.

-Information Overload (33)

Discusses problems with - and recommendations for

managing lots of information in light of ICTs

\section{Environmental Agents}

-Desire for Future Technology (64)

Discusses desires for new technology such as streaming

processes and personal- productivity enhancements. There

are several interesting contradictions in this category.

-E-learning and Training (25)

Discusses how formal learning occurs in organizations.

-Preponderance of the Web (26)

Shows that many people feel helpless if the Internet is

down. Also discusses problems with the Web such as

narrow bandwidth and inflexibility.

-Time Considerations (24)

Discusses how people differ in the way they define

real-time data and bandwidth needs

\section{Channel}

The 22 categories that compose this node of the model illustrate the reflexivity involved in channel choice. Choosing a channel proves complex and reflexive in that it is also influenced by channel norms as well as by channels used in combination. We will expand on both of these in this section describing the model. Then we'll conclude with an explanation of how the non-computermediated channel of $\mathrm{FtF}$ has become the very consciously chosen exception to the routinized computer-mediated channels that dominate organizational communication.

We cannot simply view channel choice as a linear process where people know exactly what their task is and rationally select the most appropriate channel for it. Actually, the data from this study suggests that tasks are rarely explicit and tend to be in a state of constant flux. Furthermore, it is difficult for people to explain the norms surrounding a channel without sometimes contradicting themselves. For example, several interviewees explained that they always used email to communicate with colleagues, but later in the same interviews, one added, "Well, of course, if it is important, then I will have to see the colleague FtF to discuss the issue." We suspect that contradictions like these may partially explain many of the inconsistent findings from previous deterministic empirical studies. However, even with the contradictions, some norms emerged concerning channels.

The data that compose our category called email norms appear in all 42 interviews. The empirical findings in this study confirm many of the theoretical tenets of media richness and social presence theory. For example: "When the phone rings you pretty much have to answer it, but with email, I can read the newspaper or go to the bathroom first." And "I keep email to facts, not opinions. Opinions have to be delivered, if at all possible, FtF or over the phone, so that the emotion goes with the message." 
In addition to email norms, our categories also include telephone norms, video conferencing, use of paper, Palm Pilot, fax, Internal digital knowledge bases. While the findings surrounding these channel norms tend to also confirm media richness theory, several points are especially worth noting. It appears that using email to send attached documents has virtually eliminated the need for a fax machine; but paper still has its place, especially when formal documents require signatures. Also, internal organizational Intranets have allowed people to create, though not necessarily use effectively, internal digital knowledge bases, such as Intranets or servers.

Three categories in the data set elaborated on the Webs impact on channel selection. The category called What the Web adds to the sales process suggests that it is now possible to research potential clients, competitors, and potential strategic partners by accessing public or purchased information from the Web. This can speed up the sales prospecting and qualifying processes considerably. One interviewee commented, "I can probably accommodate 10 times the amount of customers now than compared to 10 years ago because of the possibilities technology has provided." But it works the other way, too. The Web has "made customers more knowledgeable," and allows them to bypass middle-market players by going straight to a supplier. The structure of the provider/buyer relationship is a key example of AST. The Web changes the structure of the relationship since it has costs and benefits for both. While it lets the customer-service person manage more accounts, it reduces the chance that these accounts will exist at all because of the added choice that the Web gives a customer.

Not only has the Web changed the sales process, but the category we call what the Web adds to organizational processes other than sales contains data on how major changes have occurred in areas such as internal human-relations management, customer-relationship management, competitive intelligence, coordination for manufacturing, electronic commerce, and the identification of cooperators.

In the data, the Web is rarely discussed alone. It is normally mentioned as an information or communication channel that works with other channels to create a more complete communication picture. This category called sequence of media choice is the other major category area that rounds out the channel node. Since our interviewing prompts did not limit people to discussing single channels, they could discuss them however they wished. What regularly happened is that they chose to talk about them in combination. For example, when asked to explain how they find answers for a given task, interviewees often mention "going to a useful colleague first to save time," or going to the Web and using their search skills so "I'll appear more knowledgeable in front of colleagues." Another consideration was the receiver communication preference since they also mention calling or emailing knowledgeable friends. Inherent in these examples is the fact that one channel per task is the exception, not the rule.

While channel norms and the use of channels in combination provide insight into why channels justify a position on the node of the model, another key finding concerning $\mathrm{FtF}$ communication emerged in this category. We label this finding "the FtF exception to the routinization of computer-mediated communication." The data suggests that the computer-mediated channels used for communication are becoming routinized. While their routinization does not necessarily take the form of a fixed mediated channel per task, people often seek a computer-mediated channel at some point during the information and communication process. But because "the search can miss the big picture," the universal, notable exception in this data set occurs when a communication event appears critically important. The most prominent example is when the sale involves a key client or when the dollar value of the business is considered high. These interviewees always view $\mathrm{FtF}$ communication as the best channel for that task. 


\section{Communication Structure}

The communication structure node refers to those categories that shape the forces affecting a communicator. These factors vary greatly. At one extreme is little structure, which occurs under conditions of anonymity, as when a person consciously communicates (either seeking information or giving it) without disclosing their identity or assuming responsibility for what they're communicating (Scott, 1998). In one of our interviews, for example, a financial-services professional makes analyses available to potential clients on his Website because he wants to draw them to his service, but his strategy assumes they are carefully avoiding identification early in the sales process in order to forego marketing pitches. Later, he hopes, they will be enticed to give up their anonymity and approach him directly. Another example of limiting structure is seen in the practice of several of our interviewees who have different email accounts for different purposes, such as a dedicated "Spam" email account, which is not to be confused with their "real one." The capacity to create, control, and abandon these electronic identities suggests a loose structure. Work, fun, flow is a low structure category in that people play using ICTs and do not view the activity as controlled behavior.

At the other extreme is maximal structure, where the category of control lies. Here, people ensure that all parties in the communication acknowledge who they are and understand that a record of their interaction exists in an ICT like email. Our data suggests that many individuals, far from feeling constrained by this accountability, actually feel liberated, knowing that agreements can't later be blithely disavowed. The structure empowers them to collaboratively innovate, reach agreements, and make concessions with a creative flair anchored in the security of their communication. This finding is central in our data because it serves as an example of AST. It illustrates AST in that the rule to "keep agreements" becomes a resource inasmuch as an electronic audit trail - including date of communication - is left on everyone's computer to enforce it.

Four other items in this node concern structure. Hierarchy refers to the consciousness a person has when communicating with superiors. While our interviewees say little about hierarchy, when the topic does surface, they make a point of the translation strategies they use in order to adapt to higher-ups, who they assume are less skilled with ICTs and thus will prefer standard tools such as PowerPoint. One interviewee says, "If the prospect is over 45, don't just send email." After emailing, they follow up with an additional communication channel such as the telephone or FtF.

The generation gap of users and the value of the Web, meanwhile, highlight the facility that younger people think they have with technology, the common identity they share as a result, and the way they view technology as critical to their work. It must be remembered, however, that in this study of active technology users, all but three of our interviewees were under age 40, which may naturally skew their point of view.

The fourth category - information organization - shows how people select their own structure based on how readily they can store, organize, and access their data. "A piece of information becomes more valuable as it is organized, synthesized, and judged" (Repo, 1989, p. 73). Furthermore, they use these same organizing structures to judge other people's information. One interviewee, for example, says he can interpret an organization's very culture by the quality of its Website. Another interviewee says he can go into a company's Website and assesses its capabilities by examining the kind of people it has hired.

\section{Satisficing}

One assumption of decision-making in organizational science is that it is created by bounded rationality - a limited ability to control information and a struggle for interpretation in a complex environment (Anderson, 1999). Both information overload and information obsolesce contribute to this node because both conditions spur a continuing search for information (Feldman \& March, 
1981). The categories in the satisficing node have in common that they are adaptations to an environment that is moving quickly, thus people have an action bias (Browning \& Johnson, 1988). Actors sub-optimize rather than hold out for perfect decisions.

Action rationality is in keeping with the organization theory's suggested response to uncertainty. To paraphrase Weick's use of the law of requisite variety, the response to uncertainty is an uncertain structure in kind (1979). The learning by failure items exemplify this; people act quickly and make mistakes and move on as a result of the learning produced by their mis-trials (Sitkin, 1992). People also use FtF communication because it allows for learning without a lot of risk, especially when a person turns to a friend to ask, what for others, might look like a silly or inappropriate question. Testing one's beliefs with close associates allows for gauging the commonality of ideas in a relatively safe manner (Levinthal \& Warglien, 1999).

The case for action is strong in the satisficing node. The interviews show that they follow and track information constantly. Many of these agents spend four hours or more a day using ICTs and one reported spending ten hours a day on ICTs. These are examples of just-in-time learning. Changing data or multiple interpretations of what is going on drives much of the speed. When there is a fixed data point - like an exchange rate between the dollar and the yen - their work revolves around individuals actively monitoring the details surrounding their work. Satisficing is based on the assumption that more "rigorous rational-analytic models are relaxed to permit decision makers to deal with the more realistic information processing and decision making demands" (Weinberg, 1996). This illustrates the Web's role in decision- making.

March and Simon (1993) created the term satisficing to account for conditions where: "Action is goal-oriented and adaptive. But because of it's approximating and fragmented character, only a few elements of the system are adaptive at any given time; the remainder are, at least in the short run, 'givens"' (p. 191). The reliability of sources, credibility and trust category, is a good example of this adaptation. Our interviews show that people are very conscious of the need for credibility and consistently use a three-check rule for accepting data as trustworthy. This rule means that they search for information from three sources and if it agrees, it is deemed credible. People are apparently safe using this rule, as one interviewee said, "why would any one put something on the Web that isn't true?"

The value of traditional sales practices is a satisficing item in that, despite the presence of novel ICTs, people rely on things that have worked in the past. Since people have a limited capacity for assimilating new information, "they purposefully construct meaning by selectively attending to that which connects with what they already know" (Kuhlthau, 1991, p. 362).

The role of PowerPoint and the portability of ICTs are in the satisficing node in that both of them are quick and reliable ways to meet the requirements of a receiver. While PowerPoint has been criticized for homogenizing presentations (Zuckerman, 1999) and for consuming computer memory (Parker, 2001), it is a dominant organizing tool in these interviews. The combined influence of PowerPoint and FtF is captured in the following interviewee comment about the dominant communication choice: "It's still a laptop of a PowerPoint presentation, with maybe some supporting documents, with a guy traveling on a plane."

\section{Environmental Agents}

Organizational theory typically characterizes organizations and their environments as complex systems consisting of interrelated; interacting parts (Anderson, 1999; Daft \& Lewin, 1990; Simon, 1962). Given their complexity, these systems interact nonlinearly by way of feedback loops through which meanings derived in one system inform or predict activity in another system (Anderson, 1999). Our model suggests that there are various environmental factors that either enable or constrain individuals' technology use. As such, we use the term "environmental agents" 
to depict the active and structuring role these elements play. Although agency is often understood in terms of human action, we continue to rely on reflexivity as a way of extending our understanding of "agent" to include the power of the environment itself. As in the previous node descriptions, we have drawn upon principles of structuration (Giddens, 1984) as well as AST (DeSanctis \& Poole, 1994) to explicate the complexity of the environment and its role as a structuring property.

"Agency" refers to events that occur as a result of some agent's action. Even when the action is not intentional, it still reflects the capability of the agent to affect and to enact. Thus, agency implies power. Without its inertia, any given sequence of events would not take place (Cassell, 1993). Although traditional notions of agent often refer to the power of the individual to create action, we discovered that the organizational environment acts as an agent through its various enabling and constraining features. For example, while ICTs like the Web inherently provide users with more access, resources, and message transmission, they can also limit users in terms of time. When discussing email, one interviewee commented on the enabling and constraining aspect of time by stating:

The downside with email is that it not very useful when you need an immediate answer- then the telephone is a much better channel. However, email is superior when this urgency is not present, and you can do other things while waiting for an answer. I also like to use mail when I need to explain concepts or problems or ask complicated questions.

Individuals also may have extensive experience in using the Web to search for information, but the preponderance of the web and technical issues like the instability and inflexibility of the structure (e.g., narrow bandwidth), can preclude individuals from using this channel effectively. These factors and one's desire for future technology were noted by one interviewee:

The speed - and bandwidth - is definitely an issue when using the Web at work. A person cannot afford to sit around and wait. By having greater bandwidth, a person will adopt new ways of using the Web-listen to the radio, play video, etc. This will then change the way people use the Web. As another interviewee said, "By the time the ink dries, its stale information."

Although, individual experience and the training offered to people learning about new technologies like the Web creates an enabling environment, it can also constrain them if the training is inadequate or if they devalue it. For example, one interviewee discussed the relative import that members' previous experience can have in determining how they use certain technologies:

Well, it can be hard - for people who aren't used to searching on the Web, I think it'd be really difficult to get results that are useful to you. It's hard to figure out the right keywords to use, the right combinations of keywords, in order to get a return that has some valuable information in it.

We can see here the power of environmental agents to both enable and limit technology use in the way they affect people's future interactions with other users as well as their future choice of technology. Choice affects technology, which then affects how the technology is adopted and received, so that what is ultimately constructed is an iterative interplay between agent and agency, between structure and action, or, more specifically, between technology and use. This dynamic interplay between technology and use further reflects the "duality of structure" central to the structuralist point of view, which is that structures are both the medium and outcome of social practices.

AST extends traditional notions of duality to include the interaction between innate structures within advanced technologies and the structures that emerge from human action as the two interact (DeSanctis \& Poole, 1994; Orlikowski, 1992). The introduction of new technologies shapes 
and reconstructs work practices in often unanticipated ways (Coombs, Knights, \& Willmott, 1992). As stated, the structural features of a particular technology, such as bandwidth and flexibility, consist of different capabilities, rules, and resources that ultimately govern how individuals collect, use, and make sense of information (DeSanctis \& Poole, 1994). But, as we also discovered, other environmental agents, such as the physical work environment, technology adoption and company rules and policies regarding members' channel and media use, may emerge that affect how much these rules and resources are applied; so they may produce more complexity and uncertainty for knowing which channels and sources to seek in the information-gathering process. For instance, one interviewee made reference to time and how it influences his use of technology:

However, the ability to communicate asynchronously has been a revolution-being able to access and retrieve information then and there. A few years ago we had to call the manufacturer or supplier, ask them to send information about the product, etc. That obviously took more time, and while waiting for the information, we had to do other things. The work was structured differently to fit the time-delay. Now I can go out and get the information right away and start the design process.

Another individual made reference to the complexity of information received and how its degree of equivocality further affects one's choice of technology:

It really comes down to the complexity of the problem: the more complicated [it is], the more likely I am to search the Web, frankly, because I don't think my colleague would know. Information is too complex for employees. Other times, the Web is not suited to find any information because I am not able to narrow my search enough.

Here, complexity and uncertainty act as unintended consequences compelling people to find new rules and resources to organize and construct action. The reflexivity between the application of emerging rules and resources from the environment, unintended consequences, and the new rules and resources further contributes to the iterative process between environmental agents and technology use. Thus, our model lends fresh support for the duality of structure, since ICTs like the Web appear to be mediated by, and contribute to, the construction of organizational reality (Coombs et al., 1992).

\section{Summary and Conclusion}

Let us return to the themes of our research by selecting two nuggets that exemplify what we have learned and where we need to go from here. Our research question dealt with the factors that influence individuals' use when they select among the various ICTs. The findings suggest contradictions in how ICTs are perceived with respect to credibility. Our findings suggest that people will perceive the utility of ICTs differently depending on the nature of the task and the metamessage that using these sources may convey to others. For example, one interviewee indicated that he stopped using his Palm Pilot upon entering the sales field because he felt that it put distance between himself and his customers. For him, such distance further communicates a lack of credibility that, in turn, could disrupt the development and maintenance of client relationships. This finding offers additional support for the dual-capacity theory of media choice (Sitkin et al., 1992), which claims that people will often choose a channel based on its fit with the task as well as on the symbolic meanings that it conveys to others. In this case, the ICT was no longer considered a valuable tool because the user felt that it symbolically conveyed a lack of credibility.

We also found that there are certain factors influencing the sequence in which individuals use different ICTs during a given communication effort. Not only did we find that sequence of ICT use varies, but studying temporal issues is well worth pursuing. For example, with respect to environmental agents, we found additional support for the tensions that the environment brings to the organization. Our findings also offer credence to social-influence models as well as reflexive 
processes in organizations. Rather than treat the environment as an external force imposed on the organization, the environment is the doer-it becomes the agent, the structuring property that affects members' choice and use of technology. But what is also prevalent in the data is how people talk about time and how it acts as a structuring agent in channel use. Although time enables, it certainly constrains as well, and it is this tension that serves to restructure people's reality about technology. Time serves as the determinant for how we communicate and depending on the speed of the technology (its structures and capabilities), the communication attempt either saves or wastes time. Given the apparent significance of time in structuring organizational reality, future research should examine more thoroughly the temporal elements that affect members' sensemaking, their communication with one another.

Although the aim of this study was not to compare ICT use between Norway and the US, our initial reaction was that people talk about ICT use in similar. Although there are many cultural influences that can shape how individuals perceive and use ICTs, and visa versa, how ICT may shape or influence how a culture communicates (e.g. Cronin, 1996; El-Shinnaway \& Vinze, 1997; Goodman, Press, Ruth, \& Rutkowski, 1994; Maitland, 1999; Rice, D’Ambra, \& More, 1998; Straub, 1994), our descriptive data hint that this may not be the case. To further explore these initial assumptions, we have conducted a more rigorous analysis of the discourse of ICT use between these two cultures. Contrary to our initial reaction, our findings show that there in fact are differences between the countries (see Sørnes, Stephens, Sætre, \& Browning, 2004).

Similarly, the model provides scholars with a conceptual framework for looking more closely at variables and reflexive processes. Moreover, it is interesting to note the relative contribution that each node made to the overall model. As Figure 1 above indicates, "channels" was the primary discursive node in our reflexive model. One explanation for its dominance found in this study is that when people are asked about ICT use, it is often less equivocal to talk about technology in terms of channels. On the contrary, most people are not aware of the influence that external factors, such as time and training, have on their own use. As such, these issues are much more difficult to articulate and express retroactively in interviews. Yet, even with the contribution that "channels" makes in this case, it is important to reiterate that any one of the nodes within the model can preempt the dominant node to create changes in ICT use; hence its reflexive nature. Future research might delve more deeply into the model to determine the various patterns by which these nodes shift and stabilize over time.

\section{References}

Anderson, P. (1999). Complexity theory and organization science. Organization Science, 10, 216-232.

Barley, S. R. (1986). Technology as an occasion for structuring: Evidence from observations of CT scanners and the social order of radiology departments. Administration Science Quarterly, 31, 78-108.

Bastien, D.T., McPhee, R. D. \& Bolton, K.A. (1995). A study and extended theory of the structuration of climate. Communication Monographs, 62, 87-109.

Boulding, K. (1989). Social indicators of one-way transfers in organizations. In J. Anderson (Ed.), Communication yearbook, 12, (pp. 670-674). Santa Barbara, CA: Sage Publications.

Browning, L. D. \& Beyer, J. M. (1998). The structuring of shared voluntary standards in the U.S. semiconductor industry: Communicating to reach agreement. Communication Monographs, 220-243.

Browning, L. D., Beyer, J. M., \& Shetler, J. C. (1995). Building cooperation in a competitive industry: SEMATECH and the semiconductor industry. Academy of Management Journal, 38, 1, 113-151.

Browning, L.D. \& Folger, R. (1994). Communication under conditions of litigation risk: A grounded theory of plausible deniability in the Iran-Contra affair. In S. B. Sitkin \& R. J. Bies (Eds.), The legalistic organization (pp. 251-280). Thousand Oaks, CA: Sage Publications. 
Browning, L. D. \& Johnson, B. (1988). Technology and culture: Action bias effects in implementation of word processing, In G. Goldhaber (Ed.), Handbook of organizational communication (pp. 453-471). Ablex Publishing.

Browning, L. D. \& Shetler, J. C. (2000). Sematech: Saving the U.S. semiconductor industry. College Station, TX: Texas A\&M University Press.

Cassell, P. (1993). The Giddens reader. Palo Alto, CA: Stanford University Press.

Charmaz, K. (2000). Grounded theory: Objectivist and constructivist methods. In N. K. Denzin \& Y. S. Lincoln (Eds.), Handbook of qualitative research. $\left(2^{\text {nd }}\right.$ Ed.), (pp. 509-535). Thousand Oaks, CA: Sage Publications.

Chin, W. W., Gopal, A., \& Salisbury, W. D. (1997). Advancing the theory of adaptive structuration: The development of a scale to measure faithfulness of appropriation. Information Systems Research, 8, 342-367.

Contractor, N. S., \& Eisenberg, E.M. (1990). Communication networks and new media in organizations. In J. Fulk \& C. W. Steinfield (Eds.), Organizations and communication technology (pp. 143-172). Newbury Park, CA: Sage.

Contractor, N. S. \& Seibold, D. R. (1993). Theoretical frameworks for the study of structuring processes in group decision support systems: Adaptive structuration theory and self-organizing systems theory. Human Communication Research, 19, 528-563.

Coombs, R., Knight, D., \& Willmott, H. C. (1992), Culture, control and competition; Towards a conceptual framework for the study of information technology in organizations. Organization Studies, 13 (1), 5172.

Cronin, M. J. (1996). Global advantage on the Internet: From corporate connectivity to international competitiveness. New York: Van Nostrand Reinhold.

Daft, R. L. \& Lengel, R. H. (1984). Information richness: A new approach to managerial behavior and organization design, In B. M. Staw and L. L. Cummings (Eds.), Research in organizational behavior, 6 , (pp. 191-233). Greenwich, CT: JAI Press.

Daft, R. L., Lengel, R. H., \& Trevino, L. K. (1987). Message equivocality, media selection, and manager performance: Implications for information systems. MIS Quarterly, 11, 355-366.

Daft, R. L. \& Lewin, A. Y. (1990), Can organization studies begin to break out of the normal science straitjacket: An editorial essay. Organization Science, 1 (1), 1-9.

DeSanctis, G. \& Poole, M. S. (1994). Capturing the complexity in advanced technology use: Adaptive structuration theory. Organization Science, 5 (2), 121-147.

DeSanctis, G., Poole, M. S., Dickson, G. W., \& Jackson, B. M. (1993). An interpretive analysis of team use of group technologies. Journal of Organizational Computing, 3 (1), 1-29.

DeSanctis, G., Snyder, J. R., \& Poole, M. S. (1994). The meaning of the interface: A functional and holistic evaluation of a meeting software system. Decision Support Systems: The International Journal, 11, 319-335.

El-Shinnawy, M., \& Vinze, A. S. (1997). Technology, culture and persuasiveness: A Study of choice-shifts in group settings. International Journal of Human-Computer Studies, 47, 473-496.

Feldman, M. S. \& March, J. G. (1981). Information in organizations as signal and symbol. Administrative Science Quarterly, 26, 171-186.

Flanagin, A.J. \& Metzger, M. J. (2001). Internet use in the contemporary media environment. Human Communication Research, 27, 153-181.

Fulk, J., Schmitz, J., \& Steinfield, C. W. (1990). A social influence model of technology use, In J. Fulk and C. Steinfield's (Eds.) Organizations and communication technology. Newbury Park: CA: Sage. 
Fulk, J. \& Boyd. B. (1991). Emerging theories of communication in organizations. Journal of Management, $17,407-446$.

Garton, L. \& Wellman, B. (1995). Social impacts of electronic mail in organizations: A review of the research literature. In B. R. Burleson (Ed.), Communication yearbook 18, (pp. 434-453), Thousand Oaks, CA: Sage.

Giddens, A. (1979). Central problems in social theory. Berkeley, CA: University of California Press.

Giddens, A. (1984). The constitution of society. Berkeley, CA: University of California Press.

Giddens, A. (1987). Social theory and modern sociology. Stanford CA: Stanford University Press.

Giddens, A. (1990). The consequences of modernity. Stanford CA: Stanford University Press.

Glaser, B. (1978). Theoretical sensitivity. Mill Valley, CA: The Sociology Press.

Glaser, B. \& Strauss, A. (1967). The discovery of grounded theory. Chicago, IL: Aldine.

Goodman, S. E., Press, L. I., Ruth, S. R., \& Rutkowski, A. M. (1994). The global diffusion of the Internet: Patterns and problems. Communications of the ACM, 37(8), 27-31.

Hollingshead, A. B., \& Contractor, N. S. (2002). New media and organizing at the group level. In S. Livingstone \& L. Lievrouw (Eds.), Handbook of New Media (pp. 221-235). London: Sage.

Howard, L. A. \& Geist, P. (1995). Ideological positioning in organizational change: The dialectic of control in a merging organization. Communication Monographs, 62, 110-131.

Kling, R. (1996). Computerization and controversy: Value conflicts and social choices. (2nd ed.). San Diego: Academic Press.

Kuhlthau, C. C. (1996). The concept of a zone of intervention for identifying the role of intermediaries in the information search process. ASIS 1996 Annual Conference Proceedings.

Levinthal, D. A. \& Warglien, M. (1999). Landscape design: Designing for local action in complex worlds. Organization Science, 10, 342-357.

Maitland, C. (1999). Global diffusion of interactive networks. The Impact of Culture AI \& Society, 13, 34135.

March, J. G. \& Simon, H. A. (1993). Organizations (2 ${ }^{\text {nd }}$ ed.). Cambridge, MA: Blackwell Publishers.

Markus, M. L. (1990). Toward a 'critical mass' theory of interactive media. In J. Fulk \& C. Steinfield (Eds.), Organizations and communications technology, (pp. 194-218). Newbury Park, CA: Sage Publications.

Markus, M. L. \& Robey, D. (1988). Information technology and organizational change: Causal structure in theory and research. Management Science, 1, 583- 598.

Orlikowski, W. J. (2000). Using technology and constituting structures: A practice lens for studying technology in organizations. Organization Science, 11, 404-428.

Parker, I. (2001, May, 28). Absolute PowerPoint. The New Yorker, 76-87.

Patton, M. Q. (1990). Qualitative evaluations and research methods ( $2^{\text {nd }}$ ed.). London: Sage.

Polster, E. (1987). Every person's life is worth a novel. New York: Norton.

Poole, M. S., Seibold, D. \& McPhee, R. D. (1985). Group decision-making as a structural process. Quarterly Journal of Speech, 71, 74 -102.

Poole, M. S., \& DeSanctis, G. (1989). Use of group decision support systems as an appropriation process. Proceedings of the Twenty-Second Annual Hawaii International Conference on System Sciences, Vol. IV, 149-157. 
Poole, M. S., \& DeSanctis, G. (1990). Understanding the use of group decision support systems: The theory of adaptive structuration, In J. Fulk \& C. Steinfield (Eds.), Organizations and communication technology (pp. 173-193). Newbury Park, CA: Sage.

Poole, M. S., \& DeSanctis, G. (1992). Microlevel structuration in computer-supported group decisionmaking. Human Communication Research, 19 (1), 5-49.

Poole, M. S., DeSanctis, G., Kirsch, L., \& Jackson, M. (1994). Group decision support systems as facilitators of quality team efforts. In L. R. Frey (Ed.), Innovations in group facilitation techniques: Case studies of applications in naturalistic settings (pp. 299-322). Creskill, NJ: Hampton.

Ranson, S., Hinings, B. \& Greenwood, R. (1980). The structuring of organizational structures. Administrative Science Quarterly, 25, 1-17.

Reeves-Ellington, R. (1998). A mix of cultures, values, and people: An organizational case study. Human Organization. 56. 94-107.

Repo, A. J. (1989). The value of information: Approaches in economics, accounting, and management science. Journal of the American Society For Information Science, 40, 68-85.

Rice, R. E., D'Ambra, J., \& More, E. (1998). Cross-cultural comparison of organizational media evaluation and choice. Journal of Communication, 48, 3-26.

Riley, P.A. (1983). A structurationist account of political culture. Administrative Science Quarterly, 28, 414-437.

Savolainen, R. (1999). The role of the Internet in information seeking: Putting the networked services in context. Information Processing and Management, 35, 765-782.

Scott, C. R. (1998).To reveal or not to reveal: A theoretical model of anonymous communication. Communication Theory, 8, 381-407.

Scott, C. R, Quinn, L., Timmerman, E., \& Garrett, D. M. (1998). Ironic uses of group communication technology: Evidence from meeting transcripts and interviews with group decision support system users. Communication Quarterly, 46 (3), 353-374.

Scott, J. E. (1998). Organizational knowledge and the Internet. Decision Support Systems, 23, 3-17.

Short, J., Williams. E., \& Christie, B. (1976). The social psychology of telecommunications, London: Wiley.

Sitkin, S. B. (1992). Learning through failure: The strategy of small losses, In B. M. Staw \& L. L. Cummings (Eds.), Research in organizational behavior (Vol. 14, pp. 231-266). Greenwich, CT: JAI Press.

Sitkin, S.B., Sutcliff, K. M. \& Barrios-Choplin, J. R. (1992). A dual-capacity model of communication media choice in organizations. Human Communication Research, 18, 563-598.

Spear, R. \& Lea, M. (1994). Panacea or panopticon? The hidden power in computer-mediated communication. Communication Research, 21, 427-459.

Spradley, J. P. (1979). The ethnographic interview. New York: Holt Reinhart \& Winston.

Sproull, L. \& Kiesler, S. (1986). Reducing social context cues: Electronic mail in organizational communication. Management Science, 32, 1492-1512.

Steinfield, C.W. \& Fulk, J. (1990). The theory imperative. In J. Fulk \& C. Steinfield (Eds.), Organizations and communication technology. Newbury Park, CA: Sage.

Straub, D. W. (1994). The effect of culture on IT diffusion: E-mail and fax in Japan and the U.S. The Institute of Management Sciences, 5, 23-47.

Strauss, A. \& Corbin, J. (1990). Basics of qualitative research: Grounded theory procedures and techniques. Newbury Park, CA: Sage. 
Sørnes, J-O., Stephens, K. K, Sætre, A. S., \& Browning, L. D. (2004). The reflexivity between ICTs and business culture: Using Hofstede's theory for a comparison between Norway and the United States. Informing Science Journal, 7, 1-30

Taylor, R. S. (1986). Value-added processes in information systems, Norwood, NJ: Ablex Publishing.

Taylor, J. R. (2001). The "rational" organization reconsidered: An exploration of some of the organizational implications of self-organizing. Communication Theory, 11, 137-177.

Trevino, L. K., Daft, R. L., \& Lengel, R. H. (1990). Understanding managers' media choices: A symbolic interactionist perspective. In J. Fulk \& C. Steinfield (Eds.), Organizations and communication technology (pp. 71-94). Newbury Park, CA: Sage.

Webster, J. \& Trevino, L. K. (1995). Rational and social theories as complementary explanations of Communication media choice: Two policy-capturing studies. Academy of Management Journal, 38 (6), $1544-1572$.

Weick, K. E. (1979). The social psychology of organizing. Reading, MA: Addison Wesley.

Weinberg, B. H. (1996). Complexity in indexing systems-Abandonment and failure: Implications for organizing the Internet. ASIS, 1996, Annual Conference Proceedings.

Zuckerman, L. (1999, April 17). Words go right to the brain, but can they stir the heart? New York Times, A17-A19.

\section{Biographies}

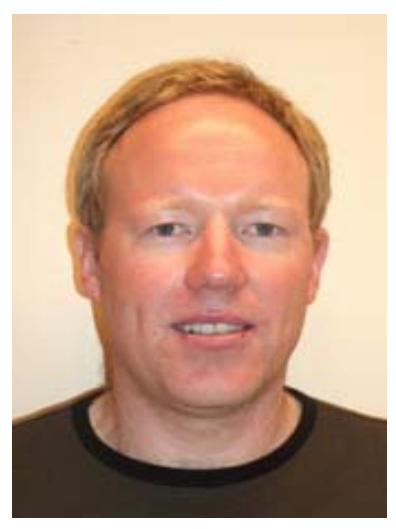

Jan-Oddvar Sørnes (Ph.D., 2004, Norwegian University of Science and Technology) is an Associate Professor at Bodø Graduate School of Business at Bodø University, Norway. Jan's research focus is on organizational communication, specifically how ICTs are used in organizations. He has 10 years of experience with e-learning and ICT use in higher education. Jan has published articles in Informing Science, Case Studies in Organizations: Ethical Perspectives and Practices, and several other edited books. He has co-authored a book titled Information and Communication Technologies in Action: Linking Theory and Narratives of Practice (2004).

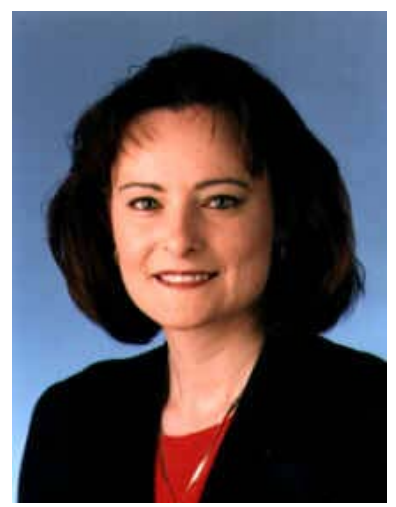

Keri K. Stephens is an assistant professor at Texas State University. Keri's research focuses on how people use technology to communicate in and between organizations. Her published work has appeared in Journal of Health Communication, Informing Science, Case Studies in Organizations: Ethical Perspectives and Practices, and several other edited books. She has also won several top paper and teaching awards. She has BS in biochemistry from Texas A\&M University and prior to returning to academia, Keri worked in technology related industries for eight years. She has recently co-authored a book titled Information and Communication Technologies in Action: Linking Theory and Narratives of Practice (2004). 


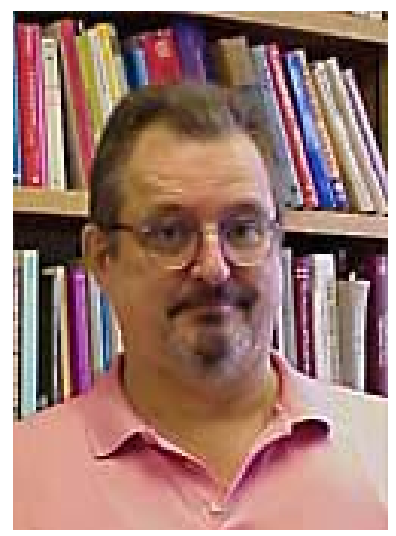

Larry Davis Browning (Ph.D., 1973, Ohio State University) is a Professor of Organizational Communication and Director of Graduate Studies in the Department of Communication Studies at the University of Texas at Austin. Larry's research on organizations is published in a variety of communication and management journals including: Communication Monographs, Academy of Management Journal, Communication Theory, Journal of Management, Communication Studies, Communication Education, Journal of Organizational Change Management, Journal of Applied Communication Research, Electronic Journal of Communication, Handbook of Organizational Communication, and Communication Yearbook 13. He has recently co-authored a book titled Information and Communication Technologies in Action:

Linking Theory and Narratives of Practice (2004).

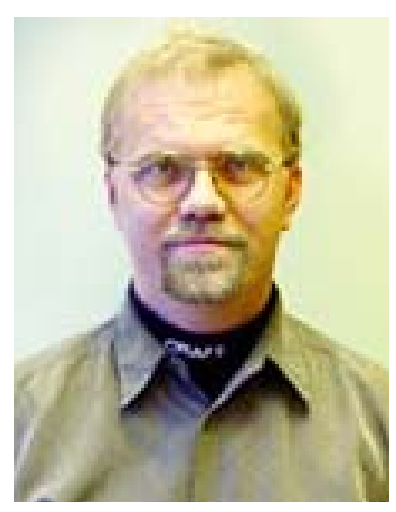

Alf Steinar Sætre (Ph.D., 1997, University of Texas at Austin) is an Associate Professor in the Department of Industrial Economics and Technology Management at The Norwegian University of Science and Technology. His research interests include information and communication technologies, organizing, communication, information management, innovation, and new venture creation. He has published articles in such journals as: Venture Capital, The International Journal of Entrepreneurship and Innovation, and Informing Science. He has recently co-authored a book titled Information and Communication Technologies in Action: Linking Theory and Narratives of Practice (2004). 